\title{
Predicting Friendship Quality in Autism Spectrum Disorders and Typical Development
}

\author{
Nirit Bauminger $\cdot$ Marjorie Solomon • \\ Sally J. Rogers
}

Published online: 29 December 2009

(C) The Author(s) 2009. This article is published with open access at Springerlink.com

\begin{abstract}
The role played by social relationship variables (attachment security; mother-child relationship qualities) and social-cognitive capacities (theory of mind) was examined in both observed friendship behaviors and in children's descriptions of friendships (age 8-12) with high functioning children with autism spectrum disorders (HFASD) $(n=44)$ and with typical development (TYP) $(n=38)$. Overall, half of the HFASD sample $(54.45 \%)$ reported maternal attachment security, corroborating data from younger children with ASD. The hypothesized predictors and their interrelations had both direct and indirect effects on friendship for both groups of children, highlighting the importance of these factors in children's friendship development and suggesting both compensatory and amplification mechanisms for friendship qualities. Practical and clinical implications are discussed for friendship support in both ASD and TYP.
\end{abstract}

Keywords HFASD - Asperger syndrome - Friendship · Attachment - Theory of mind

\section{Introduction}

Friendship involves close, emotionally intimate, and reciprocal long-term ties between children (e.g., Parker et al. 1995). The friendships of children with ASD differ in

N. Bauminger $(\square)$

School of Education, Bar Ilan University, 52900 Ramat Gan, Israel

e-mail: bauminn@mail.biu.ac.il

M. Solomon · S. J. Rogers

Mind Institute, Department of Psychiatry, UC Davis,

Sacramento, CA, USA quality and quantity from those of typically developing children (e.g., Bauminger et al. 2008a, b) owing to their limitations in affect-related resources (e.g., Hobson 2005) and deficit in the ability to form mental representations of others (i.e., theory of mind-ToM) (Tager-Flusberg 2001). Some children with ASD do develop friendships, but the mechanisms supporting friendship in ASD have not yet been explored. Given its theoretical and practical implications, this was a major aim of the current study.

\section{Mechanisms Supporting Friendship in ASD}

How might HFASD individuals negotiate a friendship, given their difficulties with emotion sharing and ToM? They may compensate for these weaker skill areas by leaning more heavily on their less impaired language and cognition. The idea that individuals with ASDs use alternative cognitive strategies to compensate for the ability to recognize and express emotions and relations that "come naturally" to non-autistic individuals has been referred to as the "logicoaffective" hypothesis (Hermelin and O'Connor 1985). In fact, verbal IQ (VIQ) was related to the understanding of social-complex emotions (e.g., empathy, embarrassment) in HFASD and not in their typical age-mates (see review in Kasari et al. 2001), and receptive language capabilities have been linked with attachment security in HFASD (Capps et al. 1994). Thus, intellectual functioning and language abilities appear to be important potential mechanisms for supporting friendship capacities in ASD.

Another variable important for friendship quality in typical development is security of attachment (e.g., Berlin et al. 2008). According to attachment theory, the quality of the parent-child relationship early in life, which is internalized into secure or insecure working models, provides a template or prototype that has direct effects on the quality 
of the child's close friendships with peers (Berlin and Cassidy, 1999). The trust and intimacy that characterize secure attachment in child-parent relationships sets the basis for expectations of similar qualities within friendships. Not surprisingly then, friendships of securely attached children are more harmonious, intimate, and responsive than those of insecurely attached children (e.g., see review in Berlin et al. 2008).

Security of attachment with a primary caretaker is a viable construct in ASD, and it may support friendship development. Consistent findings regarding secure attachment in ASD have emerged, showing that $40-50 \%$ of the children with ASD and their main caregivers are able to develop secure attachment relations (see review in Rutgers et al. 2004). There has been some question about whether attachment constructs in ASD reflect similar underlying mechanisms and outcomes as those seen in typical development. Capps et al. (1994) and Koren-Karie et al. (2009) reported that mothers of securely attached children with ASD revealed greater sensitivity to their children compared to mothers of insecurely attached children, and that sensitivity was related to security. However, van IJzendoorn et al. (2007) also found that mothers of ASD did not differ from mothers of children in other clinical groups (mental retardation, language development disorders) in their sensitivity, whereas this research group found that maternal sensitivity did not correlate with children's attachment security for the autism sample. The majority of these studies included children in preschool, and a few also examined toddlers (e.g., Naber et al. 2007); hence, the association between caregiver-child relationship qualities and security of attachment in ASD needs to be further examined, particularly in older children. In the current study, we will examine attachment quality and the link between attachment quality and self-perceived qualities of mother-child relationships and friendship characteristics in preadolescents with ASD and typical development.

Based on typical development, ToM capabilities, and more specifically false-belief understanding (i.e., that an individual's belief or representation about the world may contrast with reality), may be central to children's friendship capacities (e.g., Repacholi et al. 2003). According to Dennett (1978), false-belief understanding constitutes a litmus test of ToM, in that in such cases it becomes possible to distinguish unambiguously between the child's (true) belief and the child's awareness of someone else's different (false) belief, which sets up the basis for reciprocity. Furthermore, false-belief tasks were found to be ecologically valid, such that individual differences in falsebelief task performance correlated with individual differences in social behavior in the real world (see review in Astington 2003). A body of research has documented that children with relatively good mind-reading skills enjoy more successful social relationships (e.g., Slomkowski and Dunn 1996; Repacholi et al. 2003). ToM deficit, then, may prevent children from establishing reciprocal friendships with peers. Given their ToM and consequent perspectivetaking deficits, children and adolescents with ASD may lack complex and well-developed internal working models; consequently, even secure children with ASD may have difficulties in developing a reciprocal affective bond with a peer, leading to a different path towards friendship quality in children with ASD compared with typical controls.

Although ToM may be a potential contributor to quality of friendship, the picture is complicated because recent works have documented a link between higher ToM skills and antisocial behavior (Repacholi et al. 2003), though this link was not examined in the context of friendship nor with relation to attachment security. It may be that ToM alone will contribute less to positive friendship qualities, whereas ToM combined with security of attachment will have a greater influence on positive friendship qualities. Indeed, in the current study we examined the contribution of ToM, and its interaction with security of attachment, to friendship qualities.

Finally, as the nature of friendship develops and changes over the preadolescent age period, age may be a critical variable in understanding friendship; thus, age was the final variable examined in this study.

\section{Current Study Objectives}

The overarching goal of the present study was to investigate how attachment security, ToM, and development affect the friendship of children with ASD. We first examined attachment, mother-child relationship, and ToM differences between the groups. We next examined a hierarchical regression model using attachment security and mother-child relationship qualities, ToM, age, language ability, and their interactions on friendship quality as assessed by both child and observer report. Based on the aforementioned research, we predicted that between $40-50 \%$ of HFASD would demonstrate secure attachments to caregivers. Security of attachment and ToM capabilities were expected to contribute to friendship in both children with typical development and those with HFASD. Finally, we predicted that language ability would be a significant contributor to friendship quality in HFASD.

\section{Method}

Participants

A total of 164 children from the USA and Israel participated in the study: 44 children with HFASD $(n=24$, 
Table 1 Sample characteristics for HFASD and TYP in Israel and the USA

\begin{tabular}{|c|c|c|c|c|c|}
\hline & \multicolumn{2}{|l|}{ ASD } & \multicolumn{2}{|l|}{ TYP } & \multirow[t]{2}{*}{ Group difference $(1,77)$} \\
\hline & Israel $(n=24)$ & USA $(n=20)$ & Israel $(n=23)$ & USA $(n=15)$ & \\
\hline \multicolumn{6}{|l|}{ CA (in months) } \\
\hline$M$ & 116.00 & 125.20 & 122.87 & 123.80 & \multirow[t]{3}{*}{1.50} \\
\hline SD & 14.10 & 15.17 & 16.71 & 16.04 & \\
\hline Range & $98-151$ & $98-146$ & $98-144$ & $99-151$ & \\
\hline \multicolumn{6}{|l|}{ Verbal IQ } \\
\hline$M$ & 106.25 & 105.25 & 112.09 & 112.60 & \multirow[t]{3}{*}{1.92} \\
\hline SD & 9.84 & 16.18 & 6.93 & 14.58 & \\
\hline Range & $84-122$ & $80-133$ & $101-128$ & $94-148$ & \\
\hline \multicolumn{6}{|c|}{ Mother's education } \\
\hline$M$ & 4.66 & 5.05 & 4.63 & 5.00 & \multirow[t]{3}{*}{.81} \\
\hline SD & 1.07 & .78 & 1.33 & 1.03 & \\
\hline Male/Female & $23 / 1$ & $19 / 1$ & $22 / 1$ & $14 / 1$ & \\
\hline
\end{tabular}

Note: Verbal IQ scores are based on the Peabody Picture Vocabulary Test. Mother's education was calculated on a 6-point scale as follows: $1=$ less than 8 th grade; $2=$ some high school; $3=$ high school with diploma; $4=$ some college; $5=$ college degree such as BA; $6=$ graduate degree (e.g., masters or above)

Israel; $n=20$, USA), 38 age matched typically developing groups ( $n=23$, Israel; $n=15$, USA), and 82 friendschildren who were nominated by the 82 enrolled children as their close friends.

\section{ASD Groups}

Inclusion criteria included the all following: (1) previous DSM-IV (American Psychiatric Association 1994) diagnosis from an experienced clinician outside the study; (2) Autism Diagnostic Interview-Revised (ADI-R; Lord et al. 1994) score within the autism range as administered by the research staff; (3) a VIQ of 80 or above on the Peabody Picture Vocabulary Test (PPVT; Dunn and Dunn 1997); (4) normative reading comprehension level based on the reading subtest of the Wide Range Achievement Test 3 (WRAT 3; Wilkinson 1993) for the USA sample and on the Ma'akav (Shany et al. 2003) for the Israeli sample; and (5) an identified friend of at least 6 months' duration with whom the target child spent time together outside of school (based initially on mother report and later, during data collection, verified by the child and the friend). A detailed description of friend's selection process and characteristics can be found in Bauminger et al. (2008a). The PPVT was used to designate high functioning for the ASD sample because its scores of verbal language abilities correlate very highly with other multiple measures of general language ability and cognitive ability (Sattler 1988).

The group of children with ASD in Israel had prior clinical diagnosis of autistic disorder $(n=9 ; 37.5 \%$, one girl) or Asperger syndrome $(n=15 ; 62.5 \%)$ by a licensed psychologist unassociated with the current study. All scored above the autism cutoff on the ADI-R (Lord et al. 1994). For the US sample, all children had prior diagnosis from independent clinicians, with $7(35 \%)$ children were diagnosed with autistic disorders, and 13 (65\%, one girl) with Asperger. All 20 participants scored above the autism cutoff on the ADI-R. Inclusion of high-functioning children with either ASD or Asperger's syndrome was based on the shared social characteristics for these groups during middle childhood (see, for example, Frith 2004), and the lack of clear diagnostic boundaries that often occurs in clinical assessments.

\section{Typical Groups}

In each country, the group of children with typical development (TYP) was matched to the group of children with ASD, on maternal education, VIQ based on the PPVT (Dunn and Dunn 1997), child age, and gender (see Table 1).

\section{Measures}

We used two scales to measure attachment and motherchild relationships, two scales to measure friendship (selfreports and observations), and one scale to measure ToM. The two friendship scales allowed a multidimensional assessment of friendship combining a more subjective measure of friendship qualities (focusing on the child's perception of the quality of his/her friendship) with a more objective perspective (observation) of the dyadic quality. 


\section{Security of Attachment}

The Kerns Security Scale (KSS; Kerns et al. 1996) is a 15 -item forced-choice self-report measure designed to evaluate children's perceptions of security in mother-child relationships, including availability, reliance, and open communication with the parent. Items were rated on a 4-point scale using Harter's (1982) "Some kids...Other kids..." format. Scores across items were summed, so that children received a score on a continuous dimension of security, with higher scores indicating more secure attachment. Also, Kerns et al. (1996) suggested a cutoff score of 45 , for secure-insecure differentiation. The KSS has shown good internal consistency $(\alpha=.70)$.

\section{Mother-Child Relationship Qualities}

The Inventory of Parent and Peer Attachment (IPPA; Armsden and Greenberg 1987) was developed to assess children's perception of the positive and negative affective/ cognitive dimensions of relationships with their parents. The 25-item IPPA was rated on a 5-point Likert scale from 1(never true) to 5 (always true), yielding three broad relationship qualities: the degree of mutual trust; $(\alpha=.74)$; quality of communication $(\alpha=.76)$, and the extent of anger and alienation $(\alpha=.65)$; and an overall score $(\alpha=.87)$.

\section{Self-Report to Assess Friendship Perceptions}

The Friendship Qualities Scale (FQS; Bukowski et al. 1994) is a 23-item self-report measure assessing children's perception of friendship quality. Items are rated on a 5-point scale ranging from 1- Not true to 5- Very true. For the purpose of the current study, we used only three of the five FQS categories-closeness, intimacy, and companionship_for several reasons: (1) Closeness, intimacy, and companionship are considered the basic criteria distinguishing friends from non-friends (e.g., Parker et al. 1995). (2) We predicted positive aspects of friendship, thus the control category was excluded. (3) The help category correlated highly with the intimacy $(r=.74)$ and closeness ( $r=.55$ ) categories. The FQS subscales presented good internal reliability ( $\alpha$ between .71 and .86 in Bukowski et al. 1994, and .57-.86 in current study).

\section{Observed Dyadic Components}

We utilized the 55-item Dyadic Relationships Q-Set (DRQ; Park and Waters 1989) to evaluate dyadic behavioral dimensions (positive social orientation, responsiveness, and coordinated play), as coded from videotapes of two observed experimental friendship scenarios: construction game and drawing. For these experimental scenarios, each child came to the laboratory with his or her friend, and each dyad was videotaped for a 40-min session while participating in two different noncompetitive tasks. Children were asked to build a shared design (construction game) and to draw a shared picture (drawing task). Extensive description of the procedure can be found in (Bauminger et al. 2008a, b). Order of the construction game and shared drawing scenarios was counterbalanced.

In the current study, to reduce the number of analyses due to the relatively small number of participants, we used the three categories from the DRQ that best represented friendship relationship dimensions-coordinated play; positive social orientation; and responsiveness. Coordinated play indicates children's companionship capabilities (e.g., "partners work together to produce more complex or organized play than either would engage in alone,"); positive social interaction reflects shared enjoyment from the interaction and closeness (e.g., "partners express enjoyment at playing together;" "partners expresses mutual affection); and responsiveness reflects a sense of reciprocity (e.g., "partners endorse each other's attitudes and activity preferences"). Companionship—shared enjoyment, closeness, and reciprocity are considered in the literature as core defining characteristics of friendship (see reviews in Berndt and McCandless 2009; Bukowski et al. 2009). The self-disclosure category was excluded due to the very low frequency of this function in both study groups. The control category was excluded due to our focus on positive friendship functions. The cohesiveness and harmony categories were excluded because they were less emphasized by friendship researchers as core features of friendship (e.g., see Bukowski et al. 2009).

Two coders fluent in Hebrew and English and blind to the study hypotheses and the child diagnoses coded all videotapes from both sites into 7 piles (least characteristics $=1$ to most characteristics $=7$ ) using a fixed 5-7-913-9-7-5 forced-choice distribution, and the mean of the two observer scores was used as the variable of interest. Agreement between the two observers was tested using Pearson correlations, where sorters were variables and items were cases, with $r$ ranging between .70 and .90 (Waters and Deane 1985). We only coded videos in which the friends interacted for at least $30 \%$ of the episode. Nine dyads were dropped because they did not fulfill this coding rule ( $n=6 \mathrm{ASD} ; n=3 \mathrm{TYP}$ ).

\section{ToM: Second-Order False-Belief Attribution Task}

The Perner and Wimmer (1985) "ice-cream van story" was implemented in the current study to assess second-order false-belief attribution. It is a widely used task to assess ToM—second-order capabilities and has been used widely 
in children with ASD (e.g., Buitelaar et al. 1999). The second-order ToM task required the child to predict the thoughts of one person based on the thoughts of another (i.e., what Mary thinks John thinks). After hearing the story, subjects were asked to predict Mary's belief about John's whereabouts and "why?" Responses to the belief question were coded either as passing ("the park") or as failing (any answer but the park). In the current study, we included only the belief question, which correlated highly with the justification questions (Pearson $r=.67, p<.001$ ).

\section{Procedure}

This article reports part of a larger study that included several additional measures not reported here. Research data were collected in each PI's laboratory, one at the MIND Institute at UC Davis (Rogers), and the other at the School of Education, Bar-Ilan University (Bauminger), under the authority of the institutional review board for each university. All data from both sites were coded in Israel by one team of bilingual coders fluent in Hebrew and English. A more comprehensive description of the study procedure can be found in Bauminger et al. 2008b).

\section{Results}

\section{Security of Attachment (SA)}

To examine group differences on the continuous SA score, we performed a 2 (disability) $\times 2$ (nationality) analysis of variance (ANOVA) on the child's KSS attachment scale score. The only significant difference involved nationality, in favor of the USA sample, $F(3,78)=6.38, p<.05$, $\eta^{2}=.07 \quad(M=45.48, \quad \mathrm{SD}=7.64$ for Israel and $M=49.26, \mathrm{SD}=5.03$ for USA). Further, we assigned the children in each disability group (ASD/typical) to either a secure or insecure classification, using the cutoff score of 45 based on Kerns et al. (1996). Seventy-one percent of the TYP group were assigned to the secure classification versus $54.5 \%$ in the HFASD group; chi square analysis was nonsignificant, $\chi^{2}(1,82)=2.36, p>.05$. Thus, the HFASD group did not differ from the TYP group on this measure of attachment security.

\section{Mother-Child Relationship Quality (IPPA)}

A 2 (disability) $\times 2$ (nationality) ANOVA was carried out on the global evaluation of mother-child relationship quality measured on the IPPA, and this revealed main effects for both disability and nationality groups. As seen in Table 2, higher global quality of mother-child relationship emerged for the TYP group compared to HFASD, and for
Table 2 Means, standard deviations, and $F$ values for the disability and nationality differences between HFASD and TYP for motherchild relationship qualities (on inventory of parent and peer attachment scale)

\begin{tabular}{|c|c|c|c|c|c|c|c|c|}
\hline \multirow{2}{*}{$\begin{array}{l}\text { Relationship } \\
\text { quality }\end{array}$} & \multicolumn{2}{|l|}{ Israel } & \multicolumn{2}{|l|}{ USA } & \multicolumn{2}{|l|}{ Disability } & \multicolumn{2}{|c|}{ Nationality } \\
\hline & ASD & TYP & ASD & TYP & $F(3,78)$ & $\eta^{2}$ & $F(3,78)$ & $\eta^{2}$ \\
\hline \multicolumn{9}{|l|}{ Trust } \\
\hline$M$ & 3.93 & 4.45 & 4.38 & 4.67 & $15.01^{\mathrm{b}}$ & .16 & $10.20^{\mathrm{a}}$ & .12 \\
\hline SD & .62 & .42 & .38 & .25 & & & & \\
\hline \multicolumn{9}{|c|}{ Open communication } \\
\hline$M$ & 3.53 & 3.91 & 3.91 & 4.38 & $7.80^{\mathrm{a}}$ & .09 & $7.91^{\mathrm{a}}$ & .09 \\
\hline SD & .74 & .71 & .66 & .39 & & & & \\
\hline \multicolumn{9}{|l|}{ Alienation } \\
\hline$M$ & 2.22 & 1.98 & 2.07 & 1.81 & 2.38 & .03 & .98 & .01 \\
\hline SD & .82 & .72 & .62 & .65 & & & & \\
\hline \multicolumn{9}{|l|}{ Global score } \\
\hline$M$ & 3.75 & 4.15 & 4.10 & 4.45 & $10.81^{\mathrm{a}}$ & .12 & $8.17^{\mathrm{a}}$ & .09 \\
\hline SD & .61 & .54 & .41 & .29 & & & & \\
\hline
\end{tabular}

${ }^{\mathrm{a}} p<.01 ;{ }^{\mathrm{b}} p<.001$

children in the USA sample compared to the Israeli sample. Likewise, a 2 (disability) $\times 2$ (nationality) MANOVA on the three relationship quality categories (trust, open communication, and alienation) revealed a significant disability effect, $F(3,75)=4.97, p<.01, \eta^{2}=.17$, and a significant nationality effect, $F(3,75)=3.85, p<.05, \eta^{2}=.13$. Univariate ANOVAs demonstrated significant disability and nationality effects for open communication and trust. As can be seen in Table 2, children with TYP perceived their relationships with their mothers as more open to communication and more trustful compared to the HFASD group. Also, children in the USA outperformed children in Israel on the same quality categories.

\section{Relations Between SA and Mother-Child Qualities}

We next conducted a correlation analyses, controlling for nationality differences, between SA and mother-child relationship qualities. In both groups, higher security scores correlated with higher degrees of open communication (ASD: $r=.42, p<.01$; TYP: $r=.63, p<.001$ ); trust (ASD: $r=.49, p<.001$; TYP: $r=.70, p<.001$ ); and global mother-child relationships (ASD: $r=.57$, $p<.001$; TYP: $r=.75, p<.001$ ); and with lower degrees of alienation in mother-child relationships (ASD: $r=$ $-.53, p<.001$; TYP: $r=-.63, p<.001)$.

Group Differences in ToM and its Link with SA and Mother-Child Relationship Qualities

Fifty-seven percent of the children in the HFASD group ( 25 children out of 44 ) passed the belief question versus 
97.3\% (37 out of 38 ) of the children in the typical group, Fisher exact test, $p<.001$. Nationality differences were also significant, with children in Israel (85\%) outperforming children in the USA $(63 \%), \chi^{2}(1,82)=5.38, p<.05$.

Spearman rank correlation between ToM and IPPA was significant for all categories $(r=.26, p<.01$ for trust; $r=.24, p<.05$ for communication; $r=-.20, p<.05$ for alienation; and $r=.30, p<.01$ for global mother-child relationship). Children with better ToM false-belief understanding perceived their relationships with their mothers as more trustful, open to communication, and less detached. The link between ToM and SA was nonsignificant.

\section{Hierarchical Regressions}

We performed two series of hierarchical regression analyses for the prediction of peer friendship, by using: (a) perceived friendship qualities (FQS) including companionship, intimacy, and closeness; and (b) observed dyadic relationship qualities (DRQ) including positive social orientation, responsiveness, and coordinated play as dependent variables. Each regression series included the same predictors in the same order as follows: The first step of the analysis introduced children's VIQ and CA to partial out their possible impact on nationality and disability, which were entered in the second step. Based on attachment theory, SA and global mother-child relationship quality (IPPA-G) were entered as the third step. ToM was entered as the fourth step. The last step consisted of the interactions between SA, IPPA-G with ToM, and VIQ as possible moderators. Due to our interest in exploring whether friendship formation differs between ASD and TYP, we also examined the interaction of disability with all study predictors (SA, IPPA-G, ToM, VIQ, and CA). The addition of this examination enabled the exploration of the possible differential contributions of the predictors between the ASD/typical study groups. Lastly, given our interest in exploring whether maturation impacts friendship formation, we also examined the interaction of study predictors with CA. In all regression analyses, variables' entrance was forced in the first four steps, but in the interaction steps, variables were entered according to the significance of their contribution to the explained variance of friendship (stepwise approach, $p<.05$ ).

\section{Hierarchical Regression for Perceived Friendship Qualities (FQS)}

Overall, as seen in Table 3, the amount of variance $\left(R^{2}\right)$ explained by the combined dependent variables and their interactions was .36 for closeness, followed by intimacy $\left(R^{2}=.35\right)$ and companionship $\left(R^{2}=.28\right)$. In the first step,
Table 3 Hierarchical regression analysis of perceived friendship qualities by CA, VIQ, Attachment, ToM and their interactions

\begin{tabular}{|c|c|c|c|c|c|c|}
\hline \multirow[t]{3}{*}{ Predictors } & \multicolumn{6}{|c|}{ Friendship quality scale } \\
\hline & \multicolumn{2}{|c|}{ Companionship } & \multicolumn{2}{|c|}{ Intimacy } & \multicolumn{2}{|c|}{ Closeness } \\
\hline & $\beta$ & $\Delta R^{2}$ & $\beta$ & $\Delta R^{2}$ & $\beta$ & $\Delta R^{2}$ \\
\hline Step 1 & & $.08^{\mathrm{c}}$ & & .03 & & .02 \\
\hline $\mathrm{CA}$ & -.15 & & -.09 & & -.10 & \\
\hline VIQ & $-.21^{\mathrm{c}}$ & & .16 & & .09 & \\
\hline Step 2 & & .02 & & $.16^{\mathrm{c}}$ & & $.19^{\mathrm{a}}$ \\
\hline $\mathrm{CA}$ & -.18 & & -.16 & & $-.19^{\mathrm{c}}$ & \\
\hline VIQ & $-.24^{\mathrm{c}}$ & & .07 & & .01 & \\
\hline Nationality & .11 & & $.25^{\mathrm{b}}$ & & $.34^{\mathrm{a}}$ & \\
\hline Disability & .09 & & $.36^{\mathrm{a}}$ & & $.33^{\mathrm{a}}$ & \\
\hline Step 3 & & $.13^{\mathrm{a}}$ & & $.11^{\mathrm{a}}$ & & $.10^{\mathrm{a}}$ \\
\hline $\mathrm{CA}$ & -.12 & & -.10 & & -.13 & \\
\hline VIQ & $-.27^{\mathrm{b}}$ & & .04 & & -.04 & \\
\hline Nationality & -.03 & & .12 & & $.22^{\mathrm{c}}$ & \\
\hline Disability & -.04 & & $.24^{\mathrm{b}}$ & & $.21^{\mathrm{c}}$ & \\
\hline${ }^{1}$ IPPA-G & $.33^{\mathrm{b}}$ & & $.28^{\mathrm{b}}$ & & $.39^{\mathrm{b}}$ & \\
\hline${ }^{2} \mathrm{SA}$ & .10 & & .12 & & -.03 & \\
\hline Step 4 & & .01 & & .00 & & .01 \\
\hline CA & -.12 & & -.10 & & -.13 & \\
\hline VIQ & $-.22^{\mathrm{c}}$ & & .04 & & .00 & \\
\hline Nationality & -.07 & & .12 & & $.19^{\mathrm{c}}$ & \\
\hline Disability & .01 & & $.24^{\mathrm{b}}$ & & $.25^{\mathrm{c}}$ & \\
\hline IPPA-G & $.35^{\mathrm{b}}$ & & $.28^{\mathrm{b}}$ & & $.40^{\mathrm{b}}$ & \\
\hline SA & .09 & & .12 & & -.03 & \\
\hline${ }^{3}$ ToM & -.16 & & -.00 & & -.13 & \\
\hline Step 5 & & $.04^{\mathrm{c}}$ & & $.05^{\mathrm{c}}$ & & $.04^{\mathrm{c}}$ \\
\hline $\mathrm{CA}$ & -.05 & & -.08 & & $-.18^{\mathrm{c}}$ & \\
\hline VIQ & $-.21^{\mathrm{c}}$ & & .10 & & .00 & \\
\hline Nationality & -.10 & & .12 & & $.23^{\mathrm{c}}$ & \\
\hline Disability & .00 & & $.24^{\mathrm{b}}$ & & $.30^{\mathrm{b}}$ & \\
\hline IPPA-G & $.40^{\mathrm{b}}$ & & $.27^{\mathrm{c}}$ & & .20 & \\
\hline SA & .12 & & .15 & & -.09 & \\
\hline ToM & -.19 & & -.02 & & -.04 & \\
\hline $\mathrm{SA} \times \mathrm{ToM}$ & $-.22^{\mathrm{c}}$ & & & & $.20^{\mathrm{c}}$ & \\
\hline${ }^{4}$ Dis. $\times$ SA & & & $-.22^{\mathrm{c}}$ & & & \\
\hline$R^{2}$ & $.28^{\mathrm{b}}$ & & $.35^{\mathrm{a}}$ & & $.36^{\mathrm{a}}$ & \\
\hline
\end{tabular}

${ }^{\mathrm{a}} p<.001 ;{ }^{\mathrm{b}} p<.01 ;{ }^{\mathrm{c}} p<.05$

Note: ${ }^{1}$ IPPA-G: global mother-child relationships; ${ }^{2}$ SA-secure attachment based on the KSS; ${ }^{3} \mathrm{ToM}$ : theory of mind based on secondorder false-belief task; ${ }^{4}$ Dis = disability ASD/typical

VIQ significantly contributed to companionship, with children who showed a lower VIQ perceiving their friendship as providing more companionship. The addition of nationality and disability in the second step contributed to the explained variance of intimacy $(16 \%)$ and closeness (19\%). Lower perceived intimacy and closeness was found 
in the ASD friendship compared with typical friendship, with CA and VIQ controlled: intimacy: (ASD: $M=3.59$, $\mathrm{SD}=.73 ; \quad$ Typical: $M=4.03, \quad \mathrm{SD}=.62) ; \quad$ closeness (ASD: $M=3.92, \mathrm{SD}=.66$; Typical: $M=4.32, \mathrm{SD}=$ .49). Regarding nationality, children in the USA showed higher degrees of intimacy and closeness versus children in Israel: intimacy (USA: $M=3.94, \mathrm{SD}=.64$; Israel: $M=3.68, \mathrm{SD}=.71$ ); closeness (USA: $M=4.32, \mathrm{SD}=$ .46 ; Israel: $M=3.91, \mathrm{SD}=.79$ ).

In the third step, IPPA-G but not SA had a significant main effect for the three perceived qualities $(\beta=.39$ for closeness; $\beta=.33$ for companionship, and $\beta=.28$ for intimacy). These findings revealed that more positive mother-child relationship qualities contributed to better peer friendship qualities, independent of disability status, CA, and VIQ.

ToM and SA did not contribute significantly as main effects; however, their contribution reached significance in the interaction step. The interaction of ToM $\times \mathrm{SA}$ contributed significantly to the explained variance of companionship and closeness (4\%). To clarify the interaction, we divided the group into two subgroups-low and high in SA-according to a median of 48 on the KSS; then we examined correlations between ToM and the two friendship perceived qualities (companionship and closeness) for each attachment group (low/high). For closeness, children with high security scores revealed higher perceived closeness of their friendship $(r=.40, p>.01)$ compared to children with low security scores $(r=-.20, p>.05)$. Securely attached children with higher ToM capabilities demonstrated a higher level of closeness in their dyadic interactions. For companionship, the link between ToM and friendship was also higher in the group with high SA $(r=-.30, p<.05)$ than in the group with low SA $(r=$ $-.05, p>.05)$; however, the correlation was negative. Thus, contrary to our expectation, secure children with high ToM capabilities perceived less companionship in their friendship. This finding may suggest that attachment security accounts for more of the variance in companionship for children with lower ToM capabilities than for those with higher ToM ability.

Next, we examined the interaction between disability and predictors: This yielded only one significant interaction, between SA $\times$ disability status, which added $5 \%$ to the explained variance only for intimacy. Clarification of this interaction yielded a higher correlation between SA and intimacy in the HFASD group $(r=.49, p<.001)$ than in the typical group $(r=.23, p>.05)$. For HFASD, the contribution of SA was more important for intimacy than it was for TYP. This is a very small difference and indicates that overall the predictors have similar relationships to perceived friendship variables in the ASD and TYP groups.
Hierarchical Regression for Observed Dyadic Qualities (DRQ)

Overall, as seen in Table 4, the amount of variance explained by the combined dependent variables and their interactions was greatest for coordinated play $\left(R^{2}=.53\right)$, followed by positive social orientation and responsiveness $\left(R^{2}=.35\right.$ each $)$.

As can be seen in Table 4, the first regression step contributed to the explained variance of all three DRQ domains. More specifically, VIQ contributed significantly to all observed friendship qualities except positive social orientation, where children with higher VIQs demonstrated more responsive dyads with higher levels of coordinated play. CA contributed significantly to all observed friendship qualities, with older children demonstrating more skilled friendship qualities. In the second step, disability status significantly contributed to all DRQ domains, demonstrating higher dyadic qualities in the typical friendship (positive social orientation: $M=5.10, \mathrm{SD}=.62$; responsiveness: $M=5.33, \mathrm{SD}=.47$; and play: $M=3.90$, $\mathrm{SD}=.64$ ) than in the HFASD friendship (positive social orientation: $\quad M=4.71, \quad \mathrm{SD}=.72$; $\quad$ responsiveness: $M=4.82, \mathrm{SD}=.77$; and play: $M=3.22, \mathrm{SD}=.85)$. ASD status was thus associated with lower dyadic peer friendship qualities, beyond developmental aspects (CA, VIQ). Nationality effect was not significant. The addition of SA and IPPA-G (introduced in the third step) did not significantly contribute to the explained variance of any of the DRQ dimensions. The contribution of ToM (entered in the fourth regression step) was significant to the explained variance only for coordinated play $(4 \%)$.

SA and ToM contributed more to the explained variance of the observed friendship dyadic qualities in the interaction step than as a main effect. The only significant interaction of SA $\times$ ToM involved coordinated play. To clarify the interaction, we divided the group into two attachment groups (low/high), and then we examined correlations between ToM and coordinated play in each attachment group. A higher correlation emerged in the group with highly secure evaluations $(r=.63, p<.001)$ than in the group with lower security evaluations $(r=.22, p>.05)$. Thus, more highly secure children with higher ToM capabilities demonstrated a higher level of coordinated play.

For coordinated play, the interaction between VIQ $\times$ ToM also contributed to the explained variance. To clarify the interaction, we divided the group into two VIQ groups, lower and higher (a median score of 110 on the PPVT), and we examined correlations between ToM and coordinated play for each VIQ group. A higher correlation emerged in the lower VIQ group $(r=.44, p<.01)$ than in the higher VIQ group $(r=-.12, p>.05)$; thus, ToM capabilities 
Table 4 Hierarchical regression analysis of DRQ by CA, VIQ, attachment and ToM and their interactions
${ }^{\mathrm{a}} p<.001 ;{ }^{\mathrm{b}} p<.01 ;$

${ }^{\mathrm{c}} p<.05 ;{ }^{\dagger} p=.06$

Note: ${ }^{1}$ IPPA-G: global motherchild relationships; ${ }^{2} \mathrm{SA}$-secure attachment based on the KSS;

${ }^{3} \mathrm{ToM}$ : theory of mind based on second-order false-belief task;

${ }^{4}$ Dis $=$ disability ASD/typical

\begin{tabular}{|c|c|c|c|c|c|c|}
\hline \multirow[t]{2}{*}{ Predictors } & \multicolumn{2}{|c|}{ Positive social orientation } & \multicolumn{2}{|c|}{ Responsiveness } & \multicolumn{2}{|c|}{ Coordinated play } \\
\hline & $\Delta R^{2}$ & $\beta$ & $\Delta R^{2}$ & $\beta$ & $\overline{\Delta R^{2}}$ & $\beta$ \\
\hline Step 1 & $.14^{\mathrm{b}}$ & & $.23^{\mathrm{a}}$ & & $.33^{\mathrm{a}}$ & \\
\hline $\mathrm{CA}$ & & $.34^{\mathrm{c}}$ & & $.26^{\mathrm{b}}$ & & $.32^{\mathrm{a}}$ \\
\hline VIQ & & .16 & & $.40^{\mathrm{a}}$ & & $.48^{\mathrm{a}}$ \\
\hline Step 2 & $.07^{\mathrm{c}}$ & & $.07^{\mathrm{a}}$ & & $.08^{\mathrm{b}}$ & \\
\hline $\mathrm{CA}$ & & $.31^{\mathrm{b}}$ & & $.24^{\mathrm{c}}$ & & $.29^{\mathrm{b}}$ \\
\hline VIQ & & .09 & & $.32^{\mathrm{b}}$ & & $.40^{\mathrm{a}}$ \\
\hline Nationality & & .15 & & -.07 & & .12 \\
\hline Disability & & $.24^{\mathrm{c}}$ & & $.26^{\mathrm{b}}$ & & $.27^{\mathrm{b}}$ \\
\hline Step 3 & .04 & & .00 & & .00 & \\
\hline $\mathrm{CA}$ & & $.34^{\mathrm{b}}$ & & $.24^{\mathrm{c}}$ & & $.28^{\mathrm{b}}$ \\
\hline VIQ & & .05 & & $.31^{\mathrm{b}}$ & & $.41^{\mathrm{a}}$ \\
\hline Nationality & & .09 & & -.08 & & .13 \\
\hline Disability & & .17 & & $.25^{\mathrm{c}}$ & & $.29^{\mathrm{b}}$ \\
\hline${ }^{1} \mathrm{IPPA}-\mathrm{G}$ & & $.29^{\mathrm{c}}$ & & .05 & & -.05 \\
\hline${ }^{2} \mathrm{SA}$ & & -.13 & & -.03 & & .03 \\
\hline Step 4 & .00 & & .00 & & $.04^{\mathrm{c}}$ & \\
\hline $\mathrm{CA}$ & & $.34^{\mathrm{b}}$ & & $.24^{\mathrm{c}}$ & & $.28^{\mathrm{b}}$ \\
\hline VIQ & & .04 & & $.28^{\mathrm{b}}$ & & $.33^{\mathrm{b}}$ \\
\hline Nationality & & .09 & & -.06 & & $.18^{\mathrm{c}}$ \\
\hline Disability & & .16 & & $.23^{\mathrm{c}}$ & & $.21^{\mathrm{c}}$ \\
\hline IPPA-G & & $.29^{\mathrm{c}}$ & & .04 & & -.08 \\
\hline SA & & -.12 & & -.03 & & .04 \\
\hline${ }^{3} \mathrm{ToM}$ & & .013 & & .07 & & $.23^{\mathrm{c}}$ \\
\hline Step 5 & $.10^{\mathrm{b}}$ & & $.05^{\mathrm{c}}$ & & $.08^{\mathrm{b}}$ & \\
\hline $\mathrm{CA}$ & & $.34^{\mathrm{a}}$ & & $.19^{\mathrm{c}}$ & & $.17^{\mathrm{c}}$ \\
\hline VIQ & & .17 & & $.30^{\mathrm{b}}$ & & $.33^{\mathrm{b}}$ \\
\hline Nationality & & .13 & & -.00 & & $.29^{\mathrm{b}}$ \\
\hline Disability & & .17 & & $.26^{\mathrm{c}}$ & & $.25^{\mathrm{b}}$ \\
\hline IPPA-G & & $.24^{\dagger}$ & & .02 & & -.15 \\
\hline SA & & -.08 & & -.02 & & .00 \\
\hline ToM & & -.04 & & -.07 & & .09 \\
\hline $\mathrm{SA} \times \mathrm{ToM}$ & & & & & & $.20^{\mathrm{c}}$ \\
\hline VIQ $\times$ ToM & & & & $-.27^{\mathrm{c}}$ & & $-.26^{\mathrm{b}}$ \\
\hline${ }^{4}$ Dis. $\times$ CA & & $.34^{\mathrm{b}}$ & & & & \\
\hline $\mathrm{CA} \times \mathrm{IPPA}-\mathrm{G}$ & & $-.26^{\mathrm{c}}$ & & & & \\
\hline$R^{2}$ & & $.35^{\mathrm{a}}$ & & $.35^{\mathrm{a}}$ & & $.53^{\mathrm{a}}$ \\
\hline
\end{tabular}

Disability status $\times$ CA was significant only for positive social orientation. Clarification of this interaction through the examination of the correlation between CA (younger and older children, using the CA median of 122.5 months as a cutoff score) and positive social orientation for each group yielded a higher correlation between $\mathrm{CA}$ and positive social orientation in the typical group $(r=.61$, $p<.001)$ than in the HFASD group $(r=.11, p>.05)$. Lastly, the interaction of CA and IPPA-G significantly contributed to positive social orientation. The examination of the correlation between IPPA-G and positive social orientation in each CA group (younger/older) yielded a 
higher correlation in younger children $(r=.41, p<.01)$ than in older ones $(r=.11, p>.05)$, indicating that quality of the mother-child relationship appeared to contribute more to positive dyadic qualities of friendship in younger children than in their older counterparts.

\section{Discussion}

The unique contribution of the current study lies in its multidimensional examination of the role played by major social-emotional variables (attachment security and mother-child relationship qualities), social-cognitive capacities (ToM), and developmental factors (CA, VIQ) in observed and perceived friendships of HFASD and TYP children. A second major aim was to examine attachment security in older HFASD.

The first important finding involved the similarities in friendship development in this sample between children with TYP and children with ASD. Although disability status emerged as significant for most perceived and observed qualities of friendship, emphasizing different qualities in the two samples, overall, predictions of friendship were similar for the two groups, demonstrating similar friendship predictors and developmental patterns in typical and ASD development. Overall, the hierarchical regression analyses documented consistent effects for our hypothesized predictors (e.g., SA, IPPA-G, ToM, VIQ, and CA) and their interrelations in predicting both perceived and observed friendship qualities beyond the effects of disability status. This unexpected finding underscores the concept of autism as a developmental disorder, with relationship capacities supported by developmental accomplishments similar to those of typically developing children.

The second important finding involved the similarity of the groups on measures of attachment security, and the similar relationships that emerged between measures of attachment security and parent-child relationship qualities with friendship formation. This finding suggested that the construct of attachment security and internal working models can validly be applied to ASD. In addition, our finding that $54.5 \%$ of HFASD children perceived themselves as securely attached to their mother on the KSS in middle childhood corresponds with our hypothesis and corroborates former findings in young children with ASD, who presented $40-50 \%$ rates of secure attachment (see review in Rutgers et al. 2004). If this finding is replicated, it suggests a continuum of attachment security in ASD that should be further verified and explored by longitudinal studies because attachment security may contribute importantly to social development in broader ways than friendship.
The third important finding concerned the relationship between ToM and attachment security. In the regression analyses, ToM and SA were found to contribute to the explanation of friendship qualities only through their interrelations with the other predictors and among themselves, providing support for a moderator model. In terms of direct influences of the predictors on friendship qualities, higher verbal capabilities appeared most important to the observed friendship qualities of coordinated play and responsiveness. In addition, all observed friendship qualities seemed to improve with age, and higher quality of mother-child relationships (IPPA-G) seemed to contribute directly to the sense of closeness, intimacy, and companionship in friendships. Thus, developmental and relationship characteristics had the strongest effects on observed behavior between friends.

The interrelations between our predictors suggest that ToM and SA provide both compensatory and amplification mechanisms for friendship qualities. Higher ToM skills appear to compensate for lower VIQ in the observed friendship qualities of responsiveness and coordinated play. For coordinated play, higher ToM skills and a higher sense of attachment security enhance children's ability to coordinate play with a friend. Higher ToM skills and a higher sense of attachment security seem likewise to enhance children's sense of closeness with a friend. Both provide support for a moderator model.

Security of attachment also seems to serve as an important compensatory mechanism for two other perceived friendship qualities: intimacy and companionship. For companionship, security of attachment compensated for lower ToM skills. Findings regarding intimacy are perhaps more interesting and clinically significant. The SA was found to be more important for the development of intimacy in friendship for children with ASD than for typically developing children. This finding underscores the importance of having a high quality relationship with the mother in order for children with ASD to develop intimate friendships. It also implies that ASD children, like TYP children, generalize their models of attachment security to their friendships (Berlin and Cassidy 1999), a finding that adds validity to the construct of attachment as applied to ASD.

The current study has several limitations. First, we selected our ASD participants because of their high language scores and attainment of a close friendship. It remains unclear whether current findings apply only to this special subgroup or to the larger group of children with ASD. It should be further examined if those children on the spectrum who do not posses such close friendships present with different ToM or attachment characteristics. Also, it is important to look at friendship predictions in older ages such as adolescence, when the need for conversational 
skills increases, or in younger children (e.g., preschoolers) when ToM capabilities are less mature.

Second, although the sample studied in this work is considerable relative to those used in autism research, it remains small. This may have limited the power of our analyses to detect existing associations; therefore, caution must be taken in interpreting the present outcomes, and replication studies are needed to verify that the current findings do not stem from the number of measures used. Also, in order to reduce number of analyses we choose to focus on three aspects of friendship in each friendship measure (FQS and DRQ). Although we selected the most agreed-upon dimensions of friendship according to the literature, future studies would do well to further investigate other and perhaps more comprehensive dimensions of friendship qualities.

Third, we included only one measure of ToM, which involved a single false-belief understanding score. Indeed, we used this measure because it is considered a litmus test of ToM (Dennett 1978); it has a long history of use in studies of ToM in ASD and other groups; and it has shown ecological validity as representing individual differences in social behavior in the real world (e.g., Astington 2003). However, to more fully understand the role of ToM capacities in friendship development in both typical and atypical groups of children as reflected in "real" world social functioning, future studies should employ a more comprehensive measure of ToM as well as of verbal and cognitive skills that may help provide a fuller picture about the links between such skills and friendship.

Fourth, despite the fact that all children in the study had a clear indentified friend, we had to drop nine dyads from our analyses of the DRQ because their shared interactions lasted less than $30 \%$ of the observation time. Due to such a small number of dyads, we did not run any statistical analyses to learn more about this particular group. Yet this may imply individual differences in friendship qualities and may point to a continuum of friendship capabilities in children with HFASD.

In conclusion, security of attachment appeared more important to the development of children's friendship intimacy in ASD than in TYP. Attachment security may provide a compensatory mechanism in ASD allowing for friendship components even in the face of social-cognitive difficulties that would be expected to interfere with friendship development. This leads to two clinical recommendations concerning interactions for ASD as in TYP: (1) addressing difficulties in the parent-child relationship as they emerge by fostering responsivity and sensitivity in parents and development of clear communicative cues in the child, and (2) supporting friendship development through dyadic activities with responsive peers while assisting children with ASD to understand and empathize with the peer's perspective. Further research is needed to examine the effectiveness of various interventions for children with ASD that help them form successful friendships with their peers. It is possible that healthy friendship relations in adolescence and adulthood might help more children with ASD achieve better adult outcomes.

Acknowledgments This research was supported by a grant from the United States-Israel Binational Science Foundation (BSF) to Drs. Rogers and Bauminger. The authors would like to express their appreciation to Dee B. Ankonina for her editorial contribution and to Dov Har-Even for his statistical consultation.

Open Access This article is distributed under the terms of the Creative Commons Attribution Noncommercial License which permits any noncommercial use, distribution, and reproduction in any medium, provided the original author(s) and source are credited.

\section{References}

American Psychiatric Association. (1994). Diagnostic and statistical manual of mental disorders (4th ed.). Washington, DC: Author.

Armsden, G. C., \& Greenberg, M. T. (1987). The inventory of parent and peer attachment: Individual differences and their relationship to psychological well-being in adolescence. Journal of Youth and Adolescence, 16, 427-454.

Astington, J. W. (2003). Sometimes necessary, never sufficient: Falsebelief understanding and social competence. In B. Repacholi \& V. Slaughter (Eds.), Individual differences in theory of mind: Implications for typical and atypical development (pp. 13-38). New York: Psychology Press.

Bauminger, N., Solomon, M., Aviezer, A., Heung, K., Brown, J., \& Rogers, S. (2008a). Friendship in high-functioning children with ASD: Mixed and non-mixed Dyads. Journal of Autism and Developmental Disorders, 38, 1211-1229.

Bauminger, N., Solomon, M., Aviezer, A., Heung, K., Gazit, L., Brown, J., et al. (2008b). Friendship manifestations, dyadic qualities of friendship and friendship perception in highfunctioning preadolescents with autism spectrum disorder. Journal of Abnormal Child Psychology, 36, 135-150.

Berlin, L. J., \& Cassidy, J. (1999). Relations among relationships: Contribution from attachment theory and research. In J. Cassidy \& P. R. Shaver (Eds.), Handbook of attachment: Theory, research, and clinical applications (pp. 688-712). New York: Guilford Press.

Berlin, L. J., Cassidy, J., \& Appleyard, K. (2008). The influence of early attachment on other relationships. In J. Cassidy \& P. R. Shaver (Eds.), Handbook of attachment: Theory, research, and clinical applications (2nd ed., pp. 333-347). New York: Guilford Press.

Berndt, T. J., \& McCandless, M. A. (2009). Methods of investigating children's relationships with friends. In K. H. Rubin, W. M. Bukowski, \& B. Laursen (Eds.), Handbook of peer interactions, relationships, and groups (pp. 63-81). New York: Guilford Press.

Buitelaar, J. K., van der Wees, M., Swaab-Barneveld, H., \& van der Gaag, R. G. (1999). Theory of mind and emotion-recognition functioning in autistic spectrum disorders and in psychiatric control and normal children. Development and Psychopathology, $11,39-58$.

Bukowski, W. M., Boivin, M., \& Hoza, B. (1994). Measuring friendship quality during pre- and early adolescence: The 
development and psychometric properties of the friendship qualities scale. Journal of Social and Personal Relationships, 11, 471-484.

Bukowski, W. M., Motzoi, C., \& Meyer, F. (2009). Friendship as process, function, and outcome. In K. H. Rubin, W. M. Bukowski, \& B. Laursen (Eds.), Handbook of peer interactions, relationships, and groups (pp. 217-231). New York: Guilford Press.

Capps, L., Sigman, M., \& Mundy, P. (1994). Attachment security in children with autism. Developmental Psychopathology, 6, 249-261.

Dennett, D. (1978). Brainstorms: Philosophical essay on mind and psychology. Montgomery: Harvester Press.

Dunn, L. M., \& Dunn, L. M. (1997). Examiner's manual for the Peabody picture vocabulary test (3rd ed.). Circle Pines, MN: American Guidance Service.

Frith, U. (2004). Emanuel Miller lecture: Confusion and controversies about Asperger syndrome. Journal of Child Psychology and Psychiatry, 45, 672-686.

Harter, S. (1982). The perceived competence scale for children. Child Development, 53, 87-97.

Hermelin, B., \& O'Connor, N. (1985). Logico-affective states and nonverbal language. In E. Schopler \& G. B. Mesibov (Eds.), Communication problems in autism (pp. 283-309). New York: Plenum.

Hobson, P. (2005). Autism and emotion. In F. R. Volkmar, R. Paul, A. Klin, \& D. Cohen (Eds.), Handbook of autism and pervasive developmental disorders (pp. 406-422). Hoboken, NJ: Wiley.

Kasari, C., Chamberlain, B., \& Bauminger, N. (2001). Social emotions and social relationships in autism: Can children with autism compensate? In J. Burack, T. Charman, N. Yirmiya, \& P. Zelazo (Eds.), Perspectives on development in autism (pp. 309-323). Hillsdale, NJ: Erlbaum.

Kerns, K. A., Klepac, L., \& Cole, A. K. (1996). Peer relationships and preadolescents' perceptions of security in the child-mother relationships. Developmental Psychology, 32, 457-466.

Koren-Karie, N., Oppenheim, D., Dolev, D., \& Yirmiya, N. (2009). Mothers of securely attached children with autism spectrum disorder are more sensitive than mothers of insecurely attached children. Journal of Child Psychology and Psychiatry, 50, 643-650.

Lord, C., Rutter, M., \& LeCouteur, A. (1994). Autism diagnostic interview-revised: A revised version of a diagnostic interview for caregivers of individuals with possible pervasive developmental disorders. Journal of Autism and Developmental Disorders, 19, $185-212$

Naber, F. B. A., Swinkels, S. H. N., Buitelaar, J. K., BakermansKranenburg, M. J., van IJzendoorn, M. H., Dietz, C., et al. (2007). Attachment in toddlers with autism and other developmental disorders. Journal of Autism Developmental Disorders, 37, 1123-1138.

Park, K. A., \& Waters, E. (1989). Security of attachment and preschool friendships. Child Development, 60, 1076-1081.

Parker, J., Rubin, K. H., Price, J. M., \& DeRosier, M. E. (1995). Peer relationships, child development, and adjustment: A developmental psychopathology perspective. In D. Cicchetti \& D. J. Cohen (Eds.), Developmental psychopathology: Vol. 2. Risk, disorder and adaptation (pp. 96-161). New York: Wiley.

Perner, J., \& Wimmer, H. (1985). John thinks that Mary thinks that: Attribution of second-order beliefs by 5-to 10-year-old children. Journal of Experimental Child Psychology, 60, 689-700.

Repacholi, B., Slaughter, V., Pritchard, M., \& Gibbs, V. (2003). Theory of mind, Machiavellianism, and social functioning in childhood. In B. Repacholi \& V. Slaughter (Eds.), Individual differences in theory of mind: Implications for typical and atypical development (pp. 67-97). New York: Psychology Press.

Rutgers, A. H., Bakermans-Kranenburg, M. J., van IJzendoorn, M. H., \& van Berckelaer-Onnes, I. A. (2004). Autism and attachment: A meta-analytic review. Journal of Child Psychology and Psychiatry, 45, 1123-1134.

Sattler, J. M. (1988). Assessment of children (3rd ed.). San Diego: Author.

Shany, M., Lachman, D., Shalem, Z., Bahat, A., \& Zeiger, T. (2003). "Ma'akav:" Current mapping of reading and writing based on Israeli norms. Tel Aviv: Yesod. (Hebrew).

Slomkowski, C., \& Dunn, J. (1996). Young children's understanding of other people's beliefs and feelings and their connected communication with friends. Developmental Psychology, 32, 442-447.

Tager-Flusberg, H. (2001). A reexamination of the theory of mind hypothesis of autism. In J. Burack, T. Charman, N. Yirmiya, \& P. Zelazo (Eds.), Development and autism: Perspectives from theory and research (pp. 173-193). Hillsdale, NJ: Erlbaum Press.

van IJzendoorn, M. H., Rutgers, A. H., Bakermans-Kranenburg, M. J., Swinkels, S. H. N., van Daalen, E., Dietz, C., et al. (2007). Parental sensitivity and attachment in children with autism spectrum disorder: Comparison with children with mental retardation, with language delays, and with typical development. Child Development, 78, 597-608.

Waters, E., \& Deane, K. E. (1985). Defining and assessing individual differences in attachment relationships: Q-methodology and the organization of behavior in infancy and early childhood. In I. Bretherton, \& E. Waters (Eds.), Growing points in attachment theory and research (pp. 41-65), Monographs of the Society for Research in Child Development, 50(1-2, Serial No. 209).

Wilkinson, G. S. (1993). WRAT-3: Wide range achievement test administration manual. Wilmington, DE: Wide Range. 